\title{
Monitoring Ekg (Elektrokardiograf) Berbasis Mikrokontroller Dan Pemrograman Delphi

\author{
7.0
}

\author{
Alif Fitriani Putri \\ Program Studi Teknik Elektro Universitas \\ Muhammadiyah Surabaya, Indonesia \\ Jalan Sutorejo No. 59 Surabaya \\ alifputri64@gmail.com
}

\author{
Anang Widiantoro \\ Program Studi Teknik Elektro Universitas \\ Muhammadiyah Surabaya, Indonesia \\ Jalan Sutorejo No. 59 Surabaya \\ anang_widiantoro@yahoo.com
}

\begin{abstract}
Abstrak- Jantung merupakan salah satu organ tubuh manusia yang memegang peranan yang sangat vital dalam hidup seorang manusia. Setiap jantung memiliki empat ruang yang memiliki fungsinya masing-masing. Jantung akan bekerja melewati suatu mekanisme dengan berulang-ulang secara terus menerus yang bisa disebut dengan siklus jantung atau denyut jantung. Ketika berkontraksi, jantung akan berdenyut berirama. Hal ini terjadi karena jantung mempunyai sebuah mekanisme aliran listrik yang timbul dengan sendirinya. Aktivitas listrik jantung dapat direkam dengan elektrokardiogram (EKG) menggunakan alat atau mesin pendeteksi impuls listrik (elektrokardiograf).

Penelitian ini bertujuan untuk membuat alat yang digunakan untuk memonitoring aktifitas listrik jantung. Dalam perancangannya, alat ini menggunakan ATMEGA8 sebagai pengontrol utama. Modul AD8232 untuk mendapatkan sinyal jantung. Hasil monitoring ini akan ditampilkan pada laptop. Alat ini juga menggunakan modul bluetooth untuk mengirimkan data kedalam laptop.

Dari hasil pengukuran dan pengambilan data pada alat monitoring EKG berbasis mikrokontroller dan pemrograman delphi 7.0 yang dibandingkan dengan alat standar dari EKG menunjukkan hasil kesalahan atau error sebesar $0,83 \%$ pada pembacaan 60 BPM. Rata-rata kesalahan atau error pada alat monitoring EKG adalah $0,2 \%$.
\end{abstract}

Kata Kunci : Jantung, Modul AD8232, Elektrokardiograf, EKG, Bluetooth.

\section{PENDAHULUAN}

Jantung merupakan salah satu organ tubuh yang paling penting dan juga organ vital yang bekerja tanpa henti. Oleh karena itu, sudah sepantasnya kesehatan jantung dipelihara agar terhindar dari berbagai penyakit yang dapat merusaknya. Gejala penyakit jantung tidak dapat didiagnosis secara pasti oleh dokter. Sehingga sering disebut "silent killer", karena tidak tahu kapan terjadi, bagaimana gejalanya, dan bahkan bisa terjadi begitu saja hingga fatal akibatnya.

Penyakit yang menjadi penyebab kematian tertinggi di dunia yaitu penyakit jantung koroner. Di Indonesia setidaknya ada sekitar $0.5 \%$ warga yang terdiagnosa mengalami penyakit jantung coroner ini dan dengan tingkat kematian yang cukup tinggi di kisaran $45 \%$. Dengan persentase sekitar $0.5 \%$ dari warga Indonesia atau setara dengan 1.25 juta jiwa jika jumlah penduduk Indonesia sekitar 250 juta jiwa, dapat dikatakan bahwa penyakit jantung koroner ini termasuk pembunuh nomor satu manusia di Indonesia. Angka ini merupakan data yang tercatat di rekam medis atau dapat dikatakan penderita yang mengalami penyakit ini atau pasien melakukan check up kondisi kesehatannya ke rumah sakit. Selanjutnya bagaimana dengan sebagian masyarakat yang kurang peduli atau tidak memiliki pengetahuan tentang kesehatannya [1].

Pemeriksaan kondisi jantung dapat dilakukan dengan menggunakan Elektrokardiogram. Elektrokardiogram (EKG) atau Electrocardiogram $(E C G)$ adalah tes medis untuk mendeteksi kelainan jantung dengan mengukur aktivitas listrik yang dihasilkan oleh jantung, saat jantung berkontraksi. EKG dapat membantu mendiagnosa berbagai kondisi kesehatan seperti aritmia jantung, pembesaran jantung, peradangan jantung (perikarditis atau miokarditis), dan penyakit jantung koroner [5].

Salah satu peralatan medis atau peralatan kesehatan yang bisa digunakan untuk mendiagnosa penyakit jantung yaitu Elektrokardiograf. Elektrokardiograf akan mencatat aktivitas listrik pada otot jantung dan menampilkan data ini pada layar visual atau pada kertas print. Selanjutnya data dari alat ini didiagnosa oleh dokter ahli. Hasil EKG yang normal dari jantung memiliki ciri-ciri yang khas. Kerusakan pada otot jantung atau irama jantung yang tidak teratur 
bisa berdampak pada aktivitas listrik jantung sehingga mengubah hasil dari EKG [5].

Berdasarkan latar belakang masalah diatas, peneliti akan membuat suatu alat yang bertujuan untuk mendeteksi gangguan atau kelainan pada jantung manusia yang mudah digunakan. Maka peneliti mengambil judul tugas akhir yaitu "Monitoring EKG (Elektrokardiograf) Berbasis Mikrokontroller dan Pemrograman Delphi 7.0"

\section{BAHAN DAN METODE}

A. Jantung

Jantung merupakan organ utama sistem kardiovaskuler, berotot dan berongga, terletak di rongga toraks bagian mediastinum, diantara dua paruparu. Jantung mempunyai bentuk seperti kerucut tumpul, pada bagian bawah disebut apeks, letaknya lebih ke kiri dari garis medial, bagian tepinya pada ruang interkosta $\mathrm{V}$ kiri atau kira-kira $9 \mathrm{~cm}$ dari kiri linea medioclavicularis, sedangkan pada bagian atasnya disebut basis terletak agak kekanan tepatnya pada kosta ke III, $1 \mathrm{~cm}$ dari tepi lateral sternum. Jantung mempunyai ukuran kurang lebih sekitar panjangnya 12 $\mathrm{cm}$, lebar 8-9 $\mathrm{cm}$ dan tebalnya $6 \mathrm{~cm}$. Dan mempunyai berat sekitar 200 sampai 425 gram, untuk laki-laki sekitar 310 gram, dan untuk perempuan sekitar 225 gram.

Posisi jantung pada tubuh manusia dapat dilihat pada gambar 1 dibawah ini :

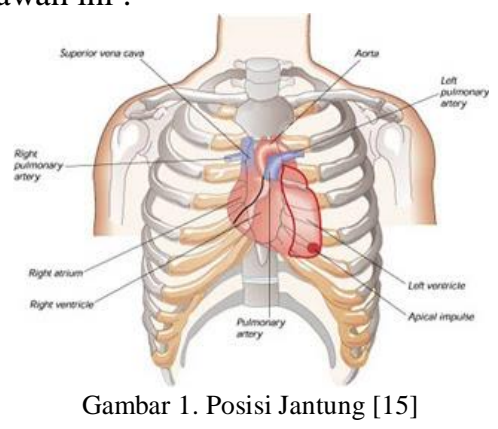

Jantung termasuk otot tubuh yang bersifat unik karena dapat membentuk impuls secara otomatis dan berkontaksi ritmis. Kemampuan jantung menghantarkan impuls listrik disebut konduksi. Adanya impuls listrik memungkinkan otot jantung mengalami depolarisasi sehingga jantung dapat berkontraksi, keadaan ini disebut eksitabilitas. Depolarisasi terjadi akibat adanya perbedaan konsentrasi muatan ion pada intrasel dan ekstrasel dalam sel otot jantung sehingga terjadi pergerakan ion menyebrang ke membran semipermeable membran sel. Adanya sistem konduksi ini memungkinkan jantung dapat berkontraksi antara atrium dan ventrikel secara sinkron.

\section{B. EKG (Elektrokardiograf)}

Aktivitas listrik jantung dapat direkam dengan alat elektrokardiograf dan hasil rekaman dari alat tersebut dinamakan elektrokardiogram. Sedangkan ilmu yang mempelajari tentang EKG disebut elektrokardiografi. Elektrokardiogram pertama kali diperkenalkan oleh seorang ilmuwan Belanda yaitu Einthoven pada tahun 1903 dengan menggunakan Galvanometer. Elektrokardiograf ini sangat berguna dalam mendiagnosa kelainan jantung seperti aritmia, iskemia, infark jantung, fungsi konduksi jantung, gangguan elektrolit.

Alat EKG (elektrokardiograf) yang sudah banyak digunakan dalam pemeriksaan kesehatan yang ada selama ini seperti pada gambar 2 dibawah ini :

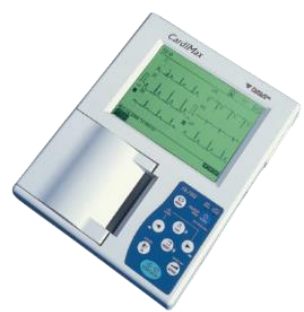

Gambar 2. EKG (Elektrokardiograf) (sumber : fukuda)

1. Elektroda Disposable

Pada umumnya bentuk elektroda disposable yang hanya satu kali dipakai dalam proses pengukuran sinyal listrik jantung, seperti pada gambar 3. dibawah ini :

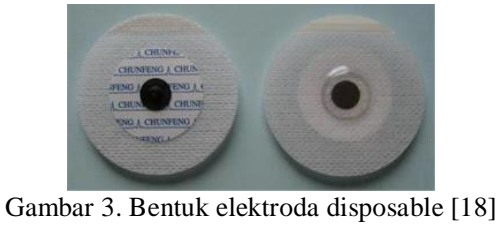

Elektroda berfungsi untuk mendeteksi adanya sinyal listrik jantung yang dipasang pada beberapa titik tertentu di permukaan tubuh. Pemantauan sinyal EKG ini akan dilakukan dengan menggunakan elektroda jenis disposable. Elektroda jenis ini dapat dipasang pada kulit dengan mudah dan dapat dilepas juga dengan mudah. (Rusyda, 2011)

2. Modul AD8232

Modul AD8232 merupakan rangkaian yang digunakan untuk mengukur aktivitas listrik jantung. Aktivitas listrik jantung ini dapat dimonitor menggunakan EKG atau Elektrokardiogram. Modul ini memberikan keluaran dalam bentuk data analog. Single Lead Heart Rate Monitor pada AD8232 berfungsi sebagai op amp untuk membantu mendapatkan 
sinyal yang jelas dari interval PR dan QT dengan mudah. Modul AD8232 yaitu blok pengkondisian sinyal terintegrasi untuk EKG dan aplikasi pengukuran biopotensial lainnya. Modul ini dirancang untuk mengekstrak, memperkuat, dan menyaring sinyal biopotensial kecil dengan kondisi noise yang minim. (Digiware, 2015).

Model dan bentuk dari modul rangkaian AD8232 seperti pada gambar 4 dibawah ini :

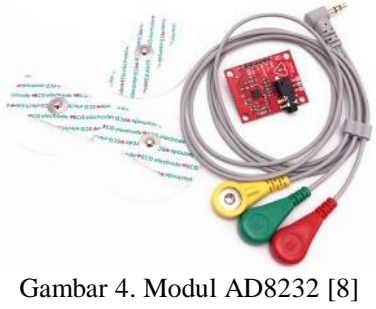

3. Mikrokontroller Atmega8

AVR ATmega8 adalah mikrokontroler CMOS 8-bit berarsitektur AVR RISC yang memiliki $8 \mathrm{~K}$ byte in-System Programmable Flash. Mikrokontroler dengan konsumsi daya rendah ini mampu mengeksekusi instruksi dengan kecepatan maksimum 16 MIPS pada 36 frekuensi $16 \mathrm{MHz}$. Jika dibandingkan dengan ATmega8L perbedaannya terletak pada besarnya tegangan yang diperlukan untuk bekerja. Untuk ATmega8 tipe L, mikrokontroler ini dapat bekerja dengan tegangan antara 2,7 - 5,5 V sedangkan untuk ATmega8 hanya dapat bekerja pada tegangan antara 4,5 - 5,5 V. ATmega8 memiliki 28 Pin, yang masing-masing pin nya memiliki fungsi yang berbeda-beda baik sebagai port maupun fungsi yang lainnya.

4. Modul Bluetooth

Bluetooth merupakan sebuah system penghubung nirkabel atau tanpa kabel yang dapat menghubungkan suatu perangkat dengan perangkat lainnya untuk saling menukar informasi maupun media. Modul Bluetooth to Serial HC 05 adalah Modul Bluetoth yang dapat diset sebagai Master ataupun sebagai Slave. Bluetooth to Serial HC 05 adalah versi pengembangan dari Modul Bluetooth to Serial HC06 yang dapat diset sebagai Master ataupun diset sebagai Slave, berbeda dengan Modul HC06 yang hanya dapat di gunakan untuk Slave saja.

5. Laptop

Laptop berfungsi untuk mengolah data yang dikirim oleh modul Bluetooth HC 05. Pengolahan data yang akan ditampilkan pada laptop menggunakan software Delphi7. Data akan ditampilkan dalam bentuk grafik sinyal EKG yang akan dapat terus dilihat oleh operator selama proses pemeriksaan berlangsung. Pada laptop juga dilengkapi dengan Bluetooth yang difungsikan sebagai receiver atau penerima.

C. Metode Penelitian

1. Diagram Mekanik Modul

a)

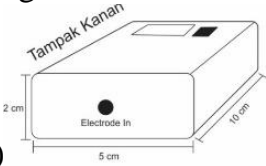

b)

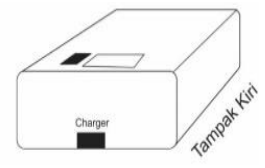

c)

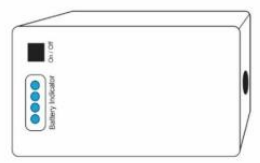

Tampak Atas

Gambar 5. Diagram mekanis rancangan alat terlihat dari a) Tampak kanan, b) Tampak kiri, c) Tampak atas

2. Diagram Blok

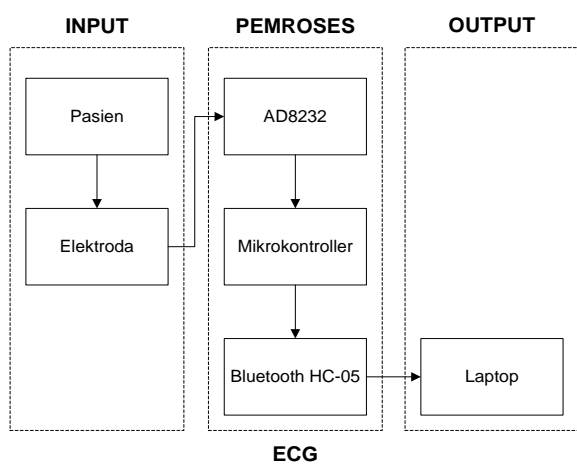

Gambar 6. Diagram blok rancangan alat monitoring EKG (Elektrokardiograf) berbasis mikrokontroller dan pemrograman delphi7.0

Penjelasan Blok Diagram: Input berasal dari elektroda disposable yang dipasang pada tubuh pasien untuk menyadap sinyal listrik jantung dari pasien. Sinyal tersebut akan diolah pada blok pemroses. Blok pemroses berisi dari modul AD8232, mikrokontroller atmega8, Bluetooth. Sinyal EKG akan diproses oleh modul rangkaian AD8232. Output dari AD8232 akan langsung dimasukkan ke pin ADC atmega8. Atmega8 akan mengubah sinyal ADC menjadi bentuk bit. Data yang sudah dirubah dalam bentuk bit akan dikirimkan ke laptop oleh Bluetooth yang disambungkan ke Port TX-RX atmega8. Data akan diterima oleh Bluetooth yang ada dalam Laptop, kemudian akan diproses menggunakan software Delphi7. Pemrosesan data yang diterima oleh delphi7 digunakan untuk 
menampilkan grafik sinyal EKG. Grafik sinyal EKG akan ditampilkan pada monitor laptop.

3. Diagram Alir

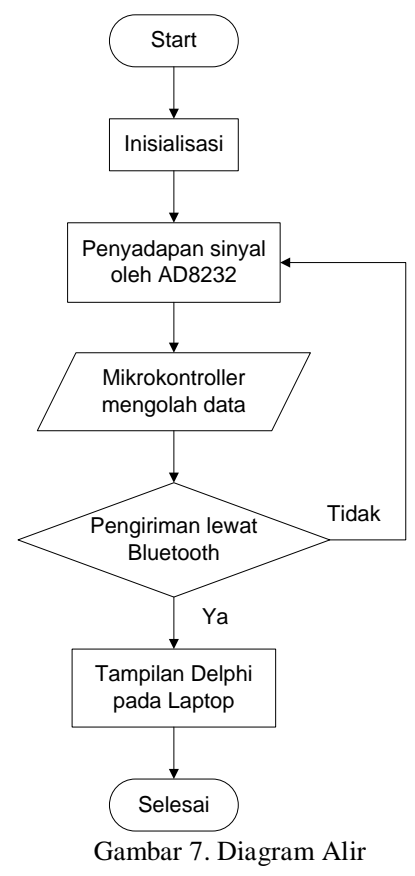

Sebelum alat dinyalakan, terlebih dahulu elektroda harus terpasang pada tubuh pasien. Elektroda berfungsi menyadap sinyal listrik jantung yang ada ditubuh pasien. Kemudian menyalakan alat, setelah elektroda terpasang semua. Sinyal listrik jantung akan diproses oleh rangkaian AD8232. Kemudian data diolah oleh mikrokontroller. Setelah pengolahan data selesai, data akan dikirim melalui Bluetooth ke laptop menggunakan program Delphi 7.0. Hasil tampilan dapat dilihat pada laptop. Tampilan monitoring yang ada dilaptop berupa grafik sinyal EKG dan BPM.

a)

\section{HASIL DAN PEMBAHASAN}

1. Rangkaian Alat

Rangkaian yang digunakan dalam pembuatan alat ini ditunjukkan pada gambar 8 dibawah ini :

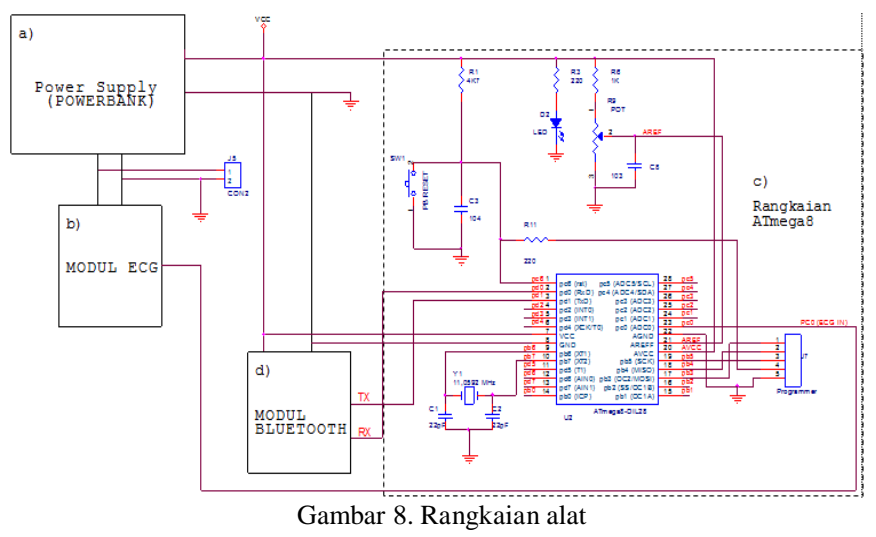

Penjelasan :

a) Power supply : rangkaian pada alat ini disupply menggunakan power bank atau baterai

b) Modul EKG : pada alat ini menggunakan modul AD8232 untuk mendeteksi sinyal listrik jantung manusia yang akan diolah oleh mikrokontroller

c) Rangkaian mikrokontroller ATmega8 : rangkaian ini digunakan untuk mengolah data dari modul EKG. Data yang diolah berupa data ADC. Inputan sinyal EKG menggunakan PortC.0 (ADC0).

d) Modul Bluetooth : modul ini digunakan untuk mengirimkan data yang sudah diolah oleh mikrokontroller ke laptop yang akan menampilkan grafik sinyal EKG. Modul bluetooth yang akan digunakan yaitu Bluetooth HC-05. Modul ini membutuhkan tegangan $+5 \mathrm{VDC}$ dan GND, menggunakan baudrate 115200. Tx dihubungkan ke PortD.0 (RxD). Rx dihubungkan ke PortD.1 (TxD).

2. Hasil Pengambilan Data

Hasil gambar dari alat monitoring EKG berbasis mikrokontroller dan pemrograman delphi yang dibuat oleh peneliti ditunjukkan pada gambar 9 dibawah ini :

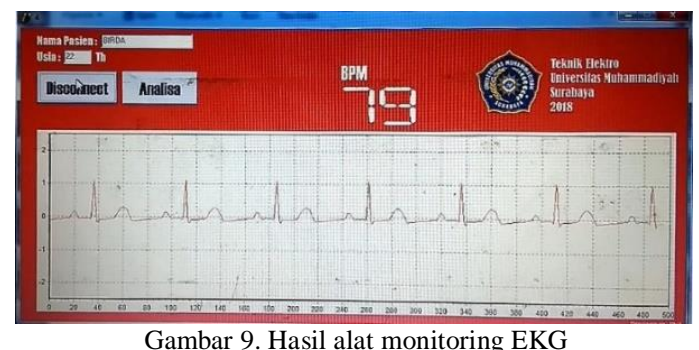

Gambar 9. Hasil alat monitoring EKG 
Tabel 1 menunjukkan hasil perbandingan pengukuran alat monitoring EKG peneliti (x) dengan alat EKG merk Fukuda Denshi (y), seperti ditunjukkan pada tabel dibawah ini :

Tabel 1 Hasil Pengambilan Data

\begin{tabular}{|c|l|c|c|c|c|c|}
\hline \multicolumn{2}{|c|}{ Pengukuran ke- } & I & II & III & IV & V \\
\hline \hline \multirow{2}{*}{1} & EKG Peneliti (x) & 81 & 81 & 81 & 81 & 81 \\
\cline { 2 - 7 } & EKG Fukuda (y) & 79 & 79 & 79 & 79 & 79 \\
\hline \multirow{2}{*}{2} & EKG Peneliti (x) & 79 & 79 & 79 & 79 & 79 \\
\cline { 2 - 8 } & EKG Fukuda (y) & 79 & 79 & 79 & 79 & 79 \\
\hline \multirow{2}{*}{3} & EKG Peneliti (x) & 81 & 81 & 81 & 81 & 81 \\
\cline { 2 - 8 } & EKG Fukuda (y) & 80 & 80 & 80 & 80 & 80 \\
\hline
\end{tabular}

Tabel 2 menunjukkan hasil pengambilan data dari pengukuran alat monitoring EKG yang dibuat peneliti dengan alat standar (ECG Simulator atau Phantom EKG), seperti ditunjukkan pada tabel dibawah ini :

Tabel 2 Hasil pengambilan data dengan alat standar

\begin{tabular}{|c|c|c|c|c|c|c|c|c|c|c|c|}
\hline \multirow{2}{*}{$\begin{array}{l}\text { Setting } \\
\text { Media } \\
\text { (BPM) }\end{array}$} & \multicolumn{6}{|c|}{ Pembacaan Alat } & \multirow[t]{2}{*}{$\begin{array}{c}\text { Rata- } \\
\text { rata }\end{array}$} & \multirow[t]{2}{*}{ SD } & \multirow{2}{*}{$\begin{array}{l}(\%) \\
\text { Error }\end{array}$} & \multirow[t]{2}{*}{$\begin{array}{l}\text { Tole } \\
\text { ransi }\end{array}$} & \multirow{2}{*}{$\frac{\mathrm{Ua}^{[6]}}{[7]}$} \\
\hline & 1 & 2 & 3 & 4 & 5 & 6 & & & & & \\
\hline 60 & 60 & 60 & 60 & 60 & 59 & 59 & 59,67 & 0,5 & 0,83 & \multirow{4}{*}{ $\pm 5 \%$} & 0,22 \\
\hline 80 & 80 & 80 & 80 & 80 & 80 & 80 & 80 & 0 & 0 & & 0 \\
\hline 100 & 100 & 100 & 100 & 100 & 100 & 100 & 100 & 0 & 0 & & \\
\hline 120 & 120 & 120 & 120 & 120 & 120 & 120 & 120 & 0 & 0 & & $0[9]$ \\
\hline
\end{tabular}

\section{KESIMPULAN}

Berdasarkan hasil pengujian pada alat monitoring EKG (Elektrokardiograf) berbasis mikrokontroller dan pemrograman Delphi 7.0, dapat diambil kesimpulan sebagai berikut:

1. Alat monitoring EKG(Elektrokardiograf) berbasis mikrokontroller dan pemrograman delphi 7.0 dibuat menggunakan modul AD8232 yang berfungsi untuk mendeteksi aktifitas listrik pada otot jantung.

2. Alat monitoring EKG(Elektrokardiograf) berbasis mikrokontroller dan pemrograman delphi 7.0 ini menggunakan ATmega8 sebagai pengolah data dan Delphi 7.0 untuk menampilan grafik sinyal ECG.

3. Pengiriman data antara modul dengan Laptop menggunakan Bluetooth HC-05
4. Berdasarkan pengambilan data dan hasil perhitungan antara alat yang dibuat dengan phantom EKG (EKG simulator) didapatkan error sebesar $0,83 \%$ pada $\mathrm{BPM}=60$ dan error sebesar 0\% pada BPM $=80,100$ dan 120. Rata-rata kesalahan atau error pada alat sebesar $0,2 \%$.

\section{DAFTAR PUSTAKA}

[1] Achmad Haerul Yusro, "Penyakit Jantung Koroner di indonesia Penyebab Kematian Nomor 1 Manusia". 2017.

[2] Ardi Winoto, "Mikrokontroller AVR ATmega8/16/32/8535 dan Pemrogramannya dengan Bahasa C pada WinAVR", Bandung : Informatika, 2008.

[3] Bahrudin, Galih, Siti, Tanty, "Terapi Modalitas Keperawatan Kardiovaskuler dan Aplikasinya", Jakarta : Trans Info Media, 2012.

[4] Barret, Kim E; Boitano, Scott; Barman, Susan M; Brooks, Hedden L; Ganong's, "Review of Medical Physiology"; Chap. 33 : 555-557, Twenty-Third Edition, Mc Graw Hill Medical Co.

[5] Carr, Brown, "Introduction to Biomedical Equipment Technology", Englewood Cliffs, NJ : Prentice Hall

Digiware "Single Lead Heart Rate Monitor AD8232". 2015.

Guyton \& Hall, 'Text Book of Medical Physiology, Unit XI" : Chap. 60, 748-760, Elevent Edition, Elsevier Saunders Inc., Philadelphia, 2006.

8] Guyton and Hall, "Fisiologi Kedokteran", ed. 11.Jakarta:EGC, 2007.

Masud, Ibnu, Dasar-Dasar Fisiologi Kardiovaskuler, 35-38, Penerbit Buku Kedokteran EGC, Jakarta, 1989.

[10] Price, A. Sylvia, "Patofisiologi, Konsep Klinis Proses-Proses Penyakit", ed.6.Jakarta:EGC, 2005.

[11] Sherwood, Lauralee, "Fisiologi Manusia. Penerbit Buku Kedokteran EGC", Jakarta, 2002.

[12] Sherwood, Lauralee, "Fisiologi Manusia, dari Sel ke Sistem", Jakarta:EGC, 2011.

[13] Sundana Krisna, "Interpretasi EKG : Pedoman Untuk Perawat", Jakarta : EGC, 2008.

[14] Tarwoto, Aryani Ratna, Wartonah, "Anatomi dan Fisiologi Untuk Mahasiswa Keperawatan", Jakarta : Trans Info Media, 2009. 